\title{
Drink and sleep like a fish: goldfish as a behavior model to study pharmaceutical effects in freshwater ecosystems
}

\author{
Valbona Aliko, ${ }^{1}$ Enis Mehmeti, ${ }^{1}$ Mihallaq Qirjo, ${ }^{1}$ Caterina Faggio ${ }^{2}$ \\ ${ }^{1}$ Department of Biology, Faculty of Natural Sciences, University of Tirana, Tirana, Albania; ${ }^{2}$ Department of Chemical, \\ Biological, Pharmaceutical and Environmental Sciences, University of Messina, Messina, Italy
}

\begin{abstract}
Behavior is a mechanism through which organisms react to internal and external stimuli to best cope with challenges in an everchanging environment. The study of animal behavior patterns in response to environmental stress/threats, is a relatively new and unexplored topic. The aim of this study is to offer a modest contribution in explaining the effects of pharmaceutical pollutants found in freshwater ecosystems, using the behavior patterns and physiology of Carassius auratus. Behavior changes were evaluated through swimming patterns, opercula and pectoral response, and rheological aggressivity. Animals were exposed for 5 weeks to water (as control), ethanol $(0.25$ and $1 \%, v / v)$, fluoxetine $(100 \mu \mathrm{g} / \mathrm{L})$ and caffeine $(50 \mathrm{mg} / \mathrm{L})$ and their short-term responses were recorded. The video has been analyzed using the open-sourced software program Track3D and EthoVision XT, which objectively quantified swimming and social behaviors. In all treatments, fish showed significantly $(\mathrm{P}<0.01)$ high levels of stress, aggressivity and hyperactivity, compared to control. An interesting fact was that for each pollutant, fish exhibited different swimming patterns, from the normal one.
\end{abstract}

Correspondence: Valbona Aliko, Department of Biology, Faculty of Natural Sciences, University of Tirana, Boulevard Zogu I, 25/1 Tirana, Albania.

E-mail: valbona.aliko@fshn.edu.al

Key words: Carassius auratus; Behavior; Pharmaceuticals; Freshwater ecosystems.

Conflict of interest: the authors declare no potential conflict of interest.

Funding: University of Tirana, Albania.

Conference presentation: part of this paper was presented at the

National SIBS Congress, Ancona, Italy, 9-10 November 2018.

Received for publication: 17 November 2018.

Revision received: 6 January 2019.

Accepted for publication: 7 January 2019.

CCopyright V. Aliko et al., 2019

Licensee PAGEPress, Italy

Journal of Biological Research 2019; $92: 7939$

doi:10.4081/jbr.2019.7939

This article is distributed under the terms of the Creative Commons Attribution Noncommercial License (by-nc 4.0) which permits any noncommercial use, distribution, and reproduction in any medium, provided the original author(s) and source are credited.
These changes in the nervous system such as stressed behavior, irregular swimming patterns, hyperactivity and aggression, are consequences of pharmaceutical pollution in freshwater bodies and as such they can be used as suitable early physiological response biomarkers to environmental stress. Monitoring of altered behavior is a great early indicator of water pollution, which can easily be applied in the best aquaculture and fishery practices.

\section{Introduction}

Pharmaceuticals are a new emerging pollutant of freshwater and marine ecosystems worldwide. In the last few years, there is an increasing awareness of researcher's community on the unintentional presence of different classes of pharmaceuticals and personal care products (PPCP) in aquatic environment compartments, column, sediments and biota. ${ }^{1,2}$ Pharmaceutically active compounds are a group of substances broadly used to treat or prevent diseases in humans and animals. Approximately 3000 pharmaceutical products are available for human use, ${ }^{3}$ and several thousand are in the process of development. Personal care products, fragrances, disinfectants, UV filters, and insect repellents, among others, encompass an even wider range of compounds. The main sources of PPCP contamination include hospital wastes, expired drugs and veterinary pharmaceuticals used to treat animals. All those end up via sewage treatment plants in aquatic and terrestrial environments. Even though pharmaceuticals are designed to use for safe treatment of health problems, and despite the fact that their concentration found in the environment range from nano grams to micrograms, there is on-growing research evidence on their adverse effects on biota and public health. ${ }^{4}$

Antibiotics, antidepressants, cytostatics and antidiabetics are some of the most important classes of pharmaceuticals found in the Albanian freshwater ecosystems ${ }^{5}$ due to their higher usage and uncontrolled management of hospital wastes and expired and unused drugs. There is evidence of the presence of antibiotics and hormones in meat (unpublished data) as a consequence of uncontrolled dosage used by livestock farmers. This unintended exposure, therefore, may result in sub-lethal developmental, neurological, endocrine, immunological and reproductive effects in wildlife.

This study aims to offer a modest contribution in explaining the effects of pharmaceutical pollutants found in freshwater ecosystems, on goldfish, Carassius auratus, as a model organism by using computational behavior models. This design was intended to test whether environmental doses of pharmaceuticals effect fish behavior and if this is the case, to establish a possible correlation between altered fish behavior and pharmaceutical pollution with intention of elucidating possible modifications of physiological mechanisms as an adaptive response to drug pollution. 


\section{Materials and Methods}

Chemicals, fluoxetine, caffeine and ethanol were purchased from Sigma Aldrich with purity higher than $98 \%$. Stock solutions were prepared freshly, in amber bottles to preserve them from light exposure. Goldfish provided by a local fish store $(\mathrm{N}=40$; body length 9-12 cm and body weight 170-200gr). They were acclimated for 1 week before treatments for 5 weeks (SSRI fluoxetine $100 \mu \mathrm{g} / \mathrm{L}$; caffeine $50 \mathrm{mg} / \mathrm{L}$, ethanol 0.25 and $1 \%$, v/v, respectively). Also, a control group (only water) were used to compare the data. Behavior evaluations were done according to Walsh ${ }^{6}$ and Hale et al., ${ }^{7}$ for 5 weeks continuously, during 3 two-hour intervals [morning (6-8 $\mathrm{AM}$ ); noon (11 AM-13 PM), and evening (4-6 PM)]. Maintenance and manipulation of animals were done in accordance with the Guide for Use and Care of Laboratory Animals (European Communities Council Directive 86/609/EEC) and national and institutional guidelines for animal welfare (Act No. 10465, 29/9/2011: "On the Veterinary Service in the Republic of Albania").

Swimming patterns were videotracked using a Fujifilm digital camera (FinePix JV300, 14.0 Mpix) positioned in front of the tank and analysed offline by Track3D and EthoVision XT software. Swimming distance and time of horizontal swimming were calculated. All behavioral endpoints were analyzed for treatment-related differences in the medians by the nonparametric Dunn's multiple comparison test. Statistical significance was set at $\mathrm{P}<0.05$ in all cases. Statistical analysis was conducted by using SPSS 20 software.

\section{Results and Discussions}

Observations of fish in both aquariums, with normal water and treated with different pharmaceuticals, proved that pharmaceuticals significantly affected goldfish behavior. Untreated fish appeared relaxed and in resting phase, with normal opercular activity, remarkable food, acoustic and rheological response. They also exhibited a characteristic pattern of swimming (Figure 1), consisting in spending lots of time at the bottom of the tank by moving vertically and horizontally, and in some cases, upside-down.

Treated fish exhibited altered food response; fish took a longer time to detect food and rushed towards it by gulping every bit, be it morning, noon or evening hours. This kind of behavior was also reported for rainbow trout. ${ }^{8}$ Probably, this greediness for food can be explained as a stress coping mechanism.

Acute exposure to caffeine produced robust anxiogenic effects, including reduced exploration, increased erratic movements and freezing behavior in goldfish tested in the novel tank diving test. ${ }^{9}$ Fish were spending more time in the bottom part of tank. In contrast, exposure of fish to fluoxetine increased vertical position, and the use of the top half of the open field when compared with the control. Fluoxetine seemed to have robust anxiolytic effects, including increased exploration and reduced erratic movements. ${ }^{10}$ This is consistent with patterns observed by Egan et al., ${ }^{11}$ who also reports an increased use of the top of the water column by zebrafish exposed to fluoxetine. Acute treatment with ethanol decreased latency to enter the upper portion of the tank, increased the number of transitions to the upper portion, and increased total time spent in that area, especially for the $1 \%$ concentration. Fish exposed to ethanol exhibited a bi-phasic effect as already is described elsewhere. ${ }^{12,13}$ This fact could be explained primarily by a low increase in blood/brain levels of ethanol followed by a motor impairing due to high blood/brain levels of alcohol reached by time. Our in vitro experiments are in line with other studies which revealed that following ethanol exposure, there is a decrease on glutamate uptake, suggesting that alcohol affects the functionality of glutamate transporters in the brain. ${ }^{14}$

So, swimming pattern seems to be drug-specific and characterized from three types of movements: horizontal, vertical and upside-down. As it is shown in Figure 1, the upside-down unusual behavior was observed in treatment with fluoxetine, but not in case of caffeine. This strange movement is probably related to aphasic kinetics of muscle twitch, which in turn may be consequent to impaired nerve- muscle coordination. ${ }^{6,15}$

Fluoxetine is a selective serotonin reuptake inhibitor (SSRI), which modulates levels of serotonin, a neurotransmitter that regulates several important physiological and behavioral processes including fear and anxiety, aggression, locomotion and feeding in fish. ${ }^{16}$ Increased levels of serotonin in the blood produce in turn producing a lighter mood by making fish less anxious and affected their swimming behavior. ${ }^{17,18}$ It can be hypothesized that inactivity induced by strong sedative effects of fluoxetine, could make fish more susceptible to predators, since the swimming speed is reduced.

Caffeine increased alertness and attentiveness by stimulating the sympathetic nervous system, affecting so significantly the respiration rate and opercular response (Figure 2). The same results are reported by other authors. ${ }^{19}$
10

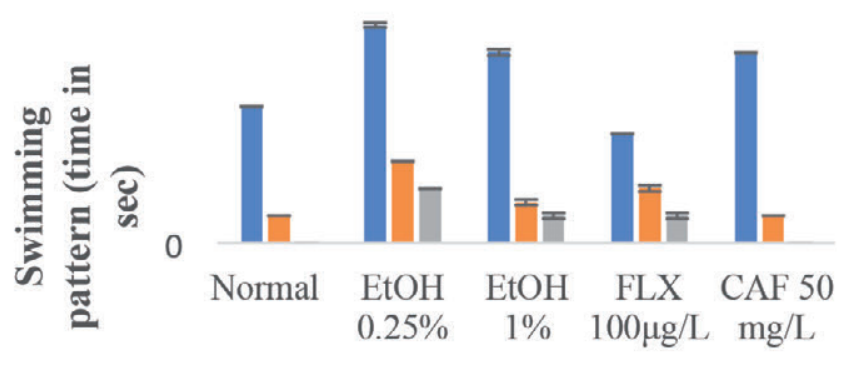

- Vertical $\quad$ Horizontal Upside-down
Figure 1. Swimming pattern of goldfish for each treatment. EtOH, ethanol; FLX, fluoxetine; CAF, caffeine.
200

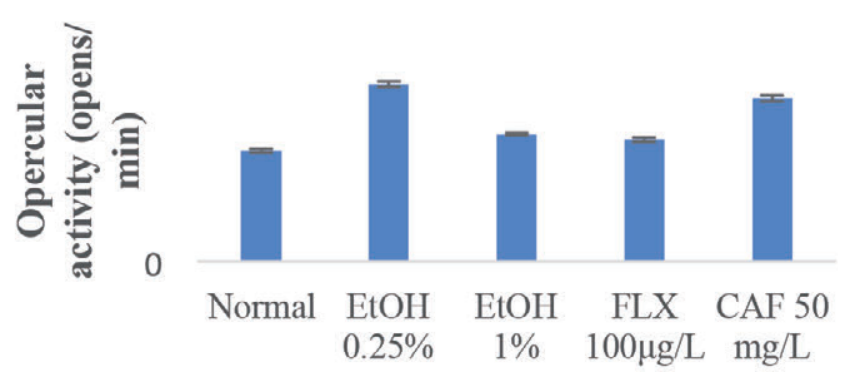

Figure 2. Mean opercular activity in goldfish exposed to different pharmaceuticals. 
In all treatments fish exhibited negative rheotaxis comparing to normal that means fish refused to response at all. Presence of pharmaceuticals in water modified significantly $(\mathrm{P}<0.01)$ the level of anxiety, perception and motor mechanisms in fish. ${ }^{20}$ Rheological response measures the velocity of fish movement to face oncoming current. Our fish exposed to fluoxetine exhibited a slower rheotaxis compared with normal 12-15 seconds, while those exposed to caffeine were much more reactive (Figure 3). Probably, drugs may affect lateral line system which can alter the ability of fish to determine changes in the oncoming flow pattern, and by so to respond properly to predators. ${ }^{21}$

Stimuli that are perceived as dangerous, in our case an acoustic/vibrational stimulus, could elicit a startle response from fish, aiding in the fish's survival. Acoustic response of goldfish resulted to be increased in case of ethanol $1 \%$ and fluoxetine treatment (Figure 4). We hypothesized that under exposure to fluoxetine or ethanol, the startle response will be differing in swimming velocity and severity. Any decrease in responsiveness to a startle stimulus in response to caffeine would suggest that this compound, found in the environment, might decrease the likelihood of a fish surviving an attack by a predator. Another interpretation is the degradation of lagena fiber responsible for hearing, space orientation and movement's coordination, due to presence of drugs. ${ }^{22}$

20

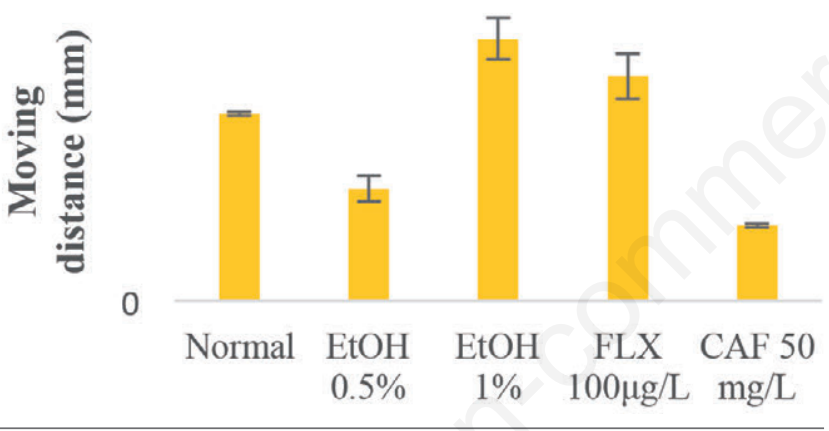

Figure 3. Mean rheological response to goldfish exposed to different pharmaceuticals.

20

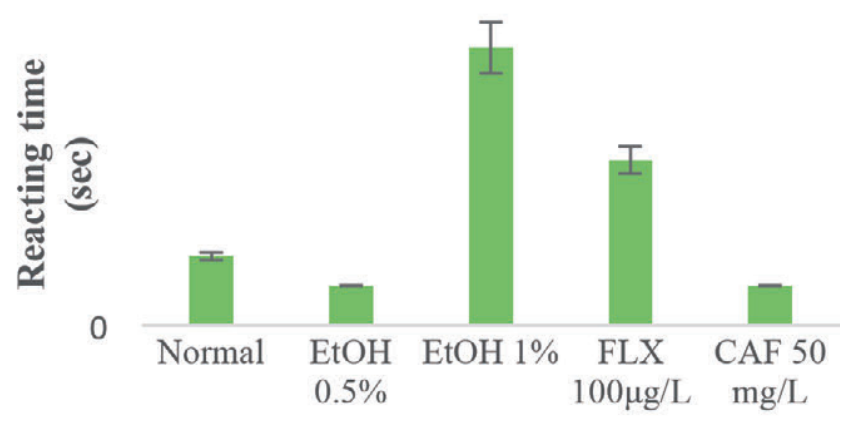

Figure 4. Mean acoustic response to goldfish exposed to different pharmaceuticals.

\section{Conclusions}

Our data revealed that the presence of psychoactive drugs in aquatic ecosystems can cause behavior modifications in goldfish. Fluoxetine, ethanol and caffeine have the potential to affect behavior in fish, by significantly impact on aquatic vertebrate populations. Fluoxetine by inhibiting the serotonin reuptake causes the elevation levels of serotonin in blood inducing a lighter mood in fish and posing them to an elevated risk from predators by compromising their survival. Caffeine, as adenosine receptor blocker, increases alertness and attentiveness of goldfish, by stimulating the sympathetic nervous system forcing the body to perform the flight or fight response. Neurotoxicity of ethanol in goldfish probably is linked with its interference with glutamate uptake receptors by altering so the fish behavior.

Behavioral analysis is perhaps the best and most objective method with which one can study the function of the brain and thus discover drug induced changes in this organ. Goldfish is a promising valid, reliable and efficacious animal model for investigating the behavior response to pharmacological pollution. Computational approach by using video-tracking as a based quantification method, can detect movements more precisely and therefore provides researchers with an important tool for the investigation of anxiety and stress behavior in this animal model.

\section{References}

1. Nikolaou A, Meric S, Fatta D. Occurrence patterns of pharmaceuticals in water and wastewater environments. Anal Bioanal Chem 2007;387:1225-34.

2. Ebele AJ, Abdallah EMA, Harrad S. Pharmaceuticals and personal care products (PPCPs) in the freshwater aquatic environment. Emerg Contaminants 2017;3:1-16.

3. Fent K, Weston AA, Caminada D. Ecotoxicology of human pharmaceuticals. Aquatic Toxicol 2006;76:122-59.

4. Navarez V, Jhon F, Jimenez C, Claudio L. Pharmaceutical products in the environment: sources, effects and risks. Vitae 2012;19:93-108.

5. Nuro A, Pine O, Shëngjergji D, et al. Determination of some antibiotics in water samples using HPLC/DAD. Optime 2016; 2:65-75.

6. Walsh SJ. Fish behavior in exploited ecosystem; ICES J Marine Sci: J Conseil 2004;61:1030-5.

7. Hale ME, Day RD, Thorsen DH, Westneat MW. Pectoral fin coordination and gait transitions in steadily swimming juvenile reef fish. J Exper Biol 2006;209:3708-18.

8. Joachim S, Argaudas S, Svante W. Does individual variation in stress responses and agonistic behavior reflect divergent stress coping strategies in juvenile rainbow trout? Physiol Biochem Zool 2005;78:715-23.

9. Sudakov SK, Medvedeva OF, Rusakova IV, Figurina IB. Effect of short-term and chronic caffeine intake on rats with various anxiety level. Bull Exp Biol Med 2001;132:1177-9.

10. Dulawa SC, Holick KA, Gundersen B, Hen R. Effects of chronic fluoxetine in animal models of anxiety and depression. Neuropsychopharmacology 2004;29:1321-30.

11. Egan RJ, Bergner CL, Hart PC, et al. Understanding behavioral and physiological phenotypes of stress and anxiety in zebrafish. Behavior Brain Res 2009;205:38-44.

12. Tran S, Gerlai R. Time-course of behavioral changes induced 
by ethanol in zebrafish (Danio rerio). Behavioral Brain Research 2013;252:204-13.

13. Pannia E, Tran E, Rampersad M, Gerlai R. Acute ethanol exposure induces behavioral differences in two zebrafish (Danio rerio) strains: A time course analysis. Behav Brain Res 2014;259:174-85.

14. Zenki KM, Mussulini BHM, Pacheco Rico E, et al. Effects of ethanol and acetaldehyde in zebrafish brain structures: An in vitro approach on glutamate uptake and on toxicity-related parameters. Toxicol in Vitro 2014;28:822-8.

15. Gerlai R, Lee V, Blaser R. Effects of acute and chronic ethanol exposure on the behavior of adult zebrafish (Danio rerio). Pharmacol Biochem Behav 2006;85:752-61.

16. Barry MJ. Effects of fluoxetine on the swimming and behavioral responses of the Arabian killifish. Ecotoxicol 2013;22: 425-32.

17. Simmons DBD, McCallum ES, Balshine S, et al. Reduced anxiety is associated with the accumulation of six serotonin reup- take inhibitors in wastewater treatment effluent exposed goldfish Carassius auratus. Scient Rep 2017;7.

18. Muir D, Simmons D, Wang X, et al. Bioaccumulation of pharmaceuticals and personal care product chemicals in fish exposed to wastewater effluent in an urban wetland. Scient Rep 2017;7.

19. Singer M, Oreschak K, Rhinehart Z, Robinson BD. Anxiolytic effects of fluoxetine and nicotine exposure on exploratory behavior in zebrafish. Peer J 2016;4:e2352.

20. Gerlai R, Lahav M, Guo S, Rosenthal A. Drinks like a fish: Zebra fish (Danio rerio) as a behavior genetic model to study alcohol effects. Pharmacol Biochem Behav 2000;67:773-82.

21. Lu Z, Xu Z, Buscher WJ. Acoustic response properties of lagena nerve fibers in sleeper Goby Dormitator Latiforns. J Compar Physiol: A. Neuroethol Sensor Neural Behav Physiol 2003;89.

22. Shrivastava S, Thakur U, Shrivastava L. Behavioural responses of Tilapia mossambica to water polluted with fly ash from coal: a laboratory study. Int J Biol 2011;3:153-60. 